\title{
A formação para matemática do professor de anos iniciais
}

\author{
Training for Mathematics teacher of the early years
}

Jaqueline de Morais Costa ${ }^{1}$ • Nilcéia Aparecida Maciel Pinheiro ${ }^{1}$ • Ercules Costa $^{2}$

Resumo: A formação do pedagogo para atuar no ensino de matemática nos Anos Iniciais do Ensino Fundamental foi o foco desta pesquisa, cujo objetivo é analisar as matrizes curriculares dos cursos de Pedagogia de instituições do Estado do Paraná e verificar o tempo disponibilizado para a formação ofertada na área de matemática. Como proposta metodológica, empregou-se uma pesquisa documental, com análises das matrizes curriculares de 59 (cinquenta e nove) instituições que oferecem o curso de Pedagogia no mesmo Estado, com foco na formação em matemática. Verificou-se que há nos currículos a inclusão de estudos pertinentes para a formação geral em matemática do futuro educador, contudo, existe um número expressivo de cursos que contemplam uma carga horária reduzida na formação em matemática. Conclui-se que as matrizes curriculares para a formação do pedagogo no Estado do Paraná têm mostrado uma abordagem tímida para a formação em matemática.

Palavras-chave: Ensino superior. Pedagogia. Currículo. Educação matemática. Formação inicial de professores.

\begin{abstract}
The formation of mathematics teachers to work in the early years of basic education is the focus of this research, and the goal is to analyze the curriculum of Pedagogy courses in institutions of the Paraná state, and to check the time available for training in the field of mathematics. As a methodological approach, we used documentary research, with an analysis of curriculum of 59 (fifty nine) institutions offering the Pedagogy course, focusing on mathematics training. It was found that there are relevant studies in the overall degree in mathematics from future education; however, there are a large number of courses that include a reduced workload in the background of mathematics. We conclude that the curriculum matrices for teachers' formation in the state of Paraná has shown a timid approach to math education.
\end{abstract}

Keywords: Higher education. Curriculum. Pedagogy. Mathematics education. Initial teachers' training.

\footnotetext{
${ }^{1}$ Universidade Tecnológica Federal do Paraná (UTFPR), Programa de Pós-Graduação em Ensino de Ciência e Tecnologia, Ponta Grossa, PR, Brasil. E-mail: <j.moraiscosta@hotmail.com>

${ }^{2}$ Faculdades Ponta Grossa, Ponta Grossa, PR, Brasil.
} 


\section{Introdução}

A proposta de discussão sobre o curso de Pedagogia, neste estudo, partiu da premissa de que se este não cumprir com as necessidades sociais de formação, acabará direta e indiretamente influenciando em todos os outros setores da educação. Não existe a intenção de minimizar as demais áreas das licenciaturas, mas sim, a de esclarecer que se a atuação do professor na escolarização inicial do indivíduo for falha, poderá interferir de forma negativa na continuidade do processo educativo. Para esta pesquisa será delimitado o estudo sobre o ensino de matemática, uma vez que o professor pedagogo, devido à sua característica de polivalência, atua como formador em diversas áreas do saber.

Os conceitos de matemática apreendidos, tão necessários para o desenvolvimento social do indivíduo, têm como objetivo contribuir para a formação da cidadania, concepção expressa claramente nas diretrizes norteadoras dos currículos, tanto para Educação Infantil, quanto para o Ensino Fundamental (BRASIL, 1997, 1998). Para cumprir o objetivo de formação, é necessário que, além de conhecer os conteúdos de matemática, o professor tenha também conhecimento de como tratá-los, a fim de que a aprendizagem do aluno se efetive.

As orientações para a composição e estruturação do currículo dos Anos Iniciais do Ensino Fundamental precisam ser contempladas durante a formação do pedagogo, considerando desde os conteúdos que precisarão ser ensinados, até as práticas de ensino desenvolvidas em sala de aula, de forma a promover a efetivação do que propõem os Parâmetros Curriculares Nacionais (PCN). Sendo assim, a questão que norteia esta investigação fica assim delineada: o que evidenciam as matrizes curriculares dos cursos de Pedagogia analisadas em relação ao tempo disponibilizado, na formação docente, para o ensino da matemática nos Anos Iniciais do Ensino Fundamental, no Estado do Paraná?

Desta forma, o objetivo do presente artigo é analisar, nas matrizes curriculares dos cursos de licenciatura em Pedagogia de instituições de ensino superior do Estado do Paraná, qual é o tempo de formação disponibilizado na preparação para atuação na educação matemática dos futuros professores de Anos Iniciais do Ensino Fundamental.

Para tanto, primeiramente, é apresentado um estudo teórico sobre o processo histórico de formação do pedagogo e uma análise acerca dos problemas de formação dos professores atuantes nos Anos Iniciais do Ensino Fundamental. Em seguida, é apresentada a análise dos dados coletados a partir das matrizes curriculares, referentes à carga horária para a formação em matemática, de Instituições de Ensino Superior (IES) que oferecem o curso de Pedagogia. Por fim, é feita a conclusão acerca da necessidade de ampliação e aprofundamento dos estudos para a matemática nos currículos de formação do pedagogo.

\section{Fundamentação teórica: o pedagogo e sua formação em matemática}

As frequentes mudanças que marcam a sociedade atual têm produzido consequências na formação em cursos voltados à educação, pois a área está demarcada por vários problemas originados na ordem política, econômica e social. Tais condições estão cada vez mais acarretando prejuízos para a qualidade da educação ofertada no Brasil, sendo que esses reflexos ficam expressos em avaliações externas nacionais e até mesmo internacionais, conforme o comentário de Michelotto (2009, p. 5): 
Um segundo problema, da maior importância, que vem permeando a questão da formação dos professores brasileiros se reflete nos maus resultados que o Brasil tem conseguido nos testes internacionais que avaliam o desempenho dos estudantes. No PISA - Programa Internacional de Avaliação dos Estudantes, que realiza pesquisa trienal de conhecimentos e competências de estudantes na faixa dos 15 anos de idade, nos países da OCDE (Organização para Cooperação e Desenvolvimento Econômico) e em países convidados, com a finalidade de produzir indicadores sobre a efetividade dos sistemas educacionais, o Brasil é colocado nas últimas posições [...].

É possível também perceber a situação da fragilidade da educação brasileira nos próprios índices nacionais, como é o caso do Índice de Desenvolvimento da Educação Básica (IDEB), cujo cálculo toma como base os dados retirados do censo escolar e do desempenho dos alunos nas avaliações externas (como a Prova e Provinha Brasil). No último IDEB divulgado, do ano de 2013, o Ensino Fundamental teve como índice 4,9 (quatro vírgula nove) para os anos iniciais e 4,0 (quatro) para os anos finais. Mais agravado se encontra o IDEB observado no Ensino Médio, que é de 3,4 (três vírgula quatro) (INEP, 2015). A meta estabelecida pelo governo federal de alcançar o índice 6,0, este considerado o ideal segundo a educação oferecida em países desenvolvidos, projeta-se para ser alcançada no ano de 2021, apenas para os anos iniciais.

Analisando os aspectos referentes aos conhecimentos em matemática, Cunha (2010) explica que os dois elementos fundamentais para o trabalho docente em ensino de matemática nos anos iniciais são domínio do conteúdo e domínio pedagógico do conteúdo. Segundo a autora, o primeiro elemento não deve ficar restrito ao que o professor dos anos iniciais precisa ensinar, este conhecimento precisa ir além. Curi (2004, p. 49) confirma esta proposição:

As considerações das especificidades de cada "área do conhecimento" com as quais o professor vai trabalhar é certamente um desafio para os programas de formação de professores. Na área de Educação Matemática, as investigações sobre o conhecimento de conteúdos matemáticos, o conhecimento didático desses conteúdos e o conhecimento dos currículos de matemática, relativos aos anos iniciais do Ensino Fundamental, têm, a nosso ver, uma forte demanda. matemática:

Curi (2005, p. 3) apresenta as competências necessárias ao docente para o ensino da A definição de competências específicas para a Educação Matemática dos futuros professores deve ter a finalidade de orientar os objetivos da formação para o ensino de Matemática, a seleção e escolha de conteúdos, a organização de modalidades pedagógicas, dos tempos e espaços da formação, a abordagem metodológica, a avaliação.

Gatti (2013, p. 54) explica que docentes são “profissionais detentores de ideias e práticas educativas fecundas, ou seja, preparados para a ação docente com consciência, conhecimentos e instrumentos". Por isso, a preocupação com a formação do professor de anos iniciais para o ensino de matemática tem sido foco de preocupação de alguns autores. 
Cunha (2010) explica que o motivo desta apreensão é porque, conforme a matemática é desenvolvida em sala de aula e os tipos de atividades propostos, certamente influenciarão a forma como estes estudantes no futuro irão encarar e relacionar os conhecimentos matemáticos. O cerne desta discussão remete à reflexão sobre a formação inicial do docente polivalente e à influência desta para o trabalho com matemática.

Sobre essa temática, Curi (2004) analisou currículos de formação de pedagogos, verificando que estes têm geralmente entre uma e três disciplinas que tratam sobre matemática. Cunha (2010) confirma esses dados, fazendo uma pesquisa com 45 cursos brasileiros de pedagogia. A autora encontrou essa mesma informação, identificando que a formação para a matemática corresponde entre 3\% a 4\% do total de carga horária de formação do pedagogo. Outro estudo, realizado por Gualberto e Almeida (2009), no qual foram analisadas cinco universidades públicas do estado de São Paulo, identificou que essa porcentagem cai para 2,1 a 3,6\%.

Gaio e Duarte (2003) complementam tais considerações, refletindo que o grande erro na formação do professor de anos iniciais é negligenciar a formação para a matemática básica, porque os conteúdos são considerados tão simplistas que dispensam uma preparação para tal. Dessa forma, é preciso ser repensada a necessidade de desenvolver os diferentes tipos de conhecimentos importantes ao professor para o ensino de matemática - de conteúdo, pedagógicos e de currículo - pois os primeiros conceitos são alicerces para conhecimentos mais complexos.

Ao se analisar a história de formação de professores polivalentes, o Curso Normal previa estudos das "quatro operações fundamentais com os números racionais na forma fracionária, algumas noções de medidas, de proporcionalidade, incluindo porcentagem, regra de três e juros" (CURI, 2004, p. 76), itens estes contemplados no currículo do Curso Primário. O que já era frágil, hoje foi simplesmente retirado dos currículos de formação de professores, com o agravante de que, hoje, estes são formados em nível superior.

A despreocupação com os objetos de ensino, enfatizando-se apenas as metodologias de como ensinar, foram pontos marcantes da década de 1970 e 1980 nos cursos de formação de professores polivalentes, conforme explana Curi (2004). Essa visão é pautada na perspectiva de que pouco se ensinam conceitos, procedimentos e a própria linguagem matemática nos cursos de formação de professores para anos iniciais, pois se concentram em "como se ensinar matemática", como se este último pudesse suprir as ausências dos anteriores, conforme explica Curi (2004).

Gatti (2013, p. 54) chama a atenção para um dos papéis primordiais da escola: "A escola exerce em seu cotidiano o papel de escolha dos conhecimentos a serem tratados com as crianças e jovens, selecionando entre os conhecimentos disponíveis, quais são essenciais, o quê incluir, quando e em qual profundidade e, também, de que forma agir pedagogicamente". Curi (2004) reflete que, devido à fragilidade na formação inicial dos docentes, o currículo de matemática nos anos iniciais, considerando objetivos de formação, conteúdos e estratégias, acaba sendo definido por assessores técnicos, ou pior, pelo que é apresentado no livro didático.

Não basta "conceituar" operações, conhecer suas propriedades, resolver técnicas operatórias, utilizá-las em problemas. É necessário também que em sua formação o professor polivalente desenvolva ou aprimore capacidades como resolver problemas, argumentar, estimar, raciocinar matematicamente, comunicar-se matematicamente. (CURI, 2004, p. 176) 
Carzola e Santana (2005), a partir de um estudo com 119 professores de anos iniciais, que estavam em formação inicial por meio de um programa do estado da Bahia, reforçam essa discussão:

[...] a concepção predominante dos professores sobre a Matemática é que esta é uma ciência exata que estuda os números e as formas, desconhecendo termos como axioma, postulado, teorema, dentre outros próprios da Matemática, bem como um escasso conhecimento da História da Matemática e de sua epistemologia. (CARZOLA; SANTANA, 2005, p. 16)

Curi (2004, p. 175) complementa:

Uma primeira observação refere-se ao significado da expressão "conhecimento sobre conteúdos matemáticos", que pode dar margem a interpretações diversas. Em primeiro lugar, entendemos que, ao separar os conhecimentos dos conteúdos matemáticos dos conhecimentos didáticos (ou pedagógicos) dos conteúdos, que são indissociáveis na prática do professor, Schulman pode ter pretendido dar destaque ao fato que ele mesmo apresentou (paradigma perdido), no sentido de que os procedimentos de ensino estavam sendo mais enfatizados do que o estudo dos objetos de ensino. Desse modo, consideramos importante o destaque apresentado por ele, embora na formulação de uma proposta de formação eles devam estar articulados.

Entende-se que nenhuma prática pedagógica poderá ser capaz de suprir a deficiência de formação. Por isso é passível de questionamento a situação de que em um curso que forma o docente, os conhecimentos que os professores precisarão desenvolver em seus alunos estejam alicerçados apenas na educação que receberam durante o Ensino Fundamental e Médio. Infelizmente, esta tem sido a realidade da formação para a matemática. Assim, a formação do pedagogo acaba sendo baseada em formas de ensinar (como), esquecendo-se do que ensinar (o quê).

Considerando os estudos realizados, é necessário ampliar as pesquisas, discussões e ações em prol da formação inicial e continuada de professores polivalentes no que tange aos conhecimentos específicos necessários para sua atuação nos anos iniciais. Na área de matemática, foi possível identificar que os docentes não adquirem a linguagem matemática durante seu processo de formação, o que tem refletido em seu trabalho em sala de aula. Dessa forma, nas leituras realizadas, percebe-se que as falas dos autores remetem à crítica sobre a desarticulação entre conhecimentos específicos e conhecimentos pedagógicos na formação de professores polivalentes.

\section{Metodologia}

Como o objetivo deste artigo é verificar como as matrizes curriculares dos cursos de Pedagogia do estado do Paraná têm disponibilizado a carga horária em formação docente 
para o ensino da matemática, optou-se pela pesquisa de natureza qualitativa. Nesse aspecto, segundo Moreira e Caleffe (2008, p. 73), a "pesquisa qualitativa explora as características dos indivíduos e cenários que não podem ser facilmente descritos numericamente". Assim, o uso dessa abordagem considera a análise baseada na interpretação de situações, pessoas e o meio onde a pesquisa se desenvolve.

Com base nos procedimentos técnicos, adotou-se a pesquisa do tipo documental, cuja característica, explicada por Marconi e Lakatos (2003), determina-se pela sua fonte de coleta de dados em documentos, que podem ser do tipo escrito ou não, sendo considerada uma fonte primária de dados.

Conforme a classificação de Marconi e Lakatos (2003), foram empregados dados escritos primários, originários de documentos de arquivos particulares. Os documentos empregados foram as matrizes curriculares dos cursos de Licenciatura em Pedagogia investigados, que foram disponibilizados pelas instituições por meio de página da internet. Como foi feita uma análise das matrizes em vigor, esta pesquisa é definida como um estudo de documentos contemporâneos.

Os documentos analisados são categorizados como escritos e oficiais, pois uma matriz curricular é considerada como documento obrigatório de um curso ofertado por uma Instituição de Ensino Superior (IES).

O objeto de estudo da presente pesquisa se configurou nas IES do estado do Paraná que atualmente oferecem o curso de Pedagogia. O Estado conta com 91 (noventa e uma) instituições em que o curso é oferecido, sendo que foi possível localizar a matriz curricular de 59 (cinquenta e nove) cursos, representando $64,8 \%$ do universo da pesquisa.

Os cursos de Pedagogia foram localizados por meio do sistema e-mec ${ }^{3}$, no qual são cadastrados pelo Ministério da Educação todos os cursos autorizados e/ou reconhecidos. Para esta pesquisa foram selecionados cursos presenciais, pois se entende que a formação à distância envolve outros componentes que não foram contemplados neste estudo. Também foram considerados apenas cursos considerados pelo sistema como "em atividade", ou seja, que estão ainda em oferta.

Dentro da análise, as instituições envolvidas foram nominadas como CP1, CP2, CP3,[...], CP91, em que CP significa Curso de Pedagogia.

Em uma análise inicial, foram categorizados todos os cursos de Pedagogia presenciais e, portanto, todos referenciados conforme a nomenclatura apresentada anteriormente. Em uma segunda análise, foram selecionados apenas os cursos em que foi possível o acesso à Matriz Curricular, os quais serão apresentados no capítulo seguinte.

\section{Análise das Matrizes Curriculares}

\section{Oferta de cursos pela iniciativa pública ou privada}

Em uma primeira análise, as instituições pesquisadas foram classificadas como públicas ou privadas. Essa organização teve como objetivo verificar como tem sido a oferta dos cursos, para ampliação da análise realizada. Os resultados encontrados estão presentes no Quadro 1.

\footnotetext{
${ }^{3}$ Disponível em: <http://emec.mec.gov.br/>. Acesso em: 5 fev. 2016.
} 
Quadro 1. Oferta dos cursos de Pedagogia

\begin{tabular}{|c|c|}
\hline Instituição de Ensino Superior (IES) & Iniciativa de oferta \\
\hline СР1; CP4; СР5; СР12; СР13; СР14; СР17; СР22; СР23; СР90 & Pública \\
\hline 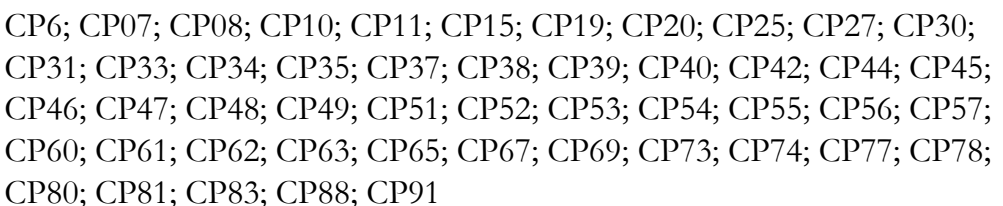 & Privada \\
\hline
\end{tabular}

Fonte: Elaborado pelos autores.

Considerando os cursos analisados, das 59 IES que ofertam Pedagogia, apenas 16,67\% são oferecidos pela iniciativa pública. Esse perfil vem ao encontro da oferta de ensino superior no Estado do Paraná, se verificada a quantidade de IES de origem pública e privada no período de 1981 a 2011, conforme pode ser visualizado na Tabela 1.

Tabela 1. Evolução da abertura de Instituições de Ensino Superior no Paraná

\begin{tabular}{cccccccc}
\hline \multirow{2}{*}{ Ano } & \multicolumn{5}{c}{ Instituições públicas } & & \\
\cline { 2 - 5 } & Federal & Estadual & Municipal & Total públicas & Instituições privadas & Total \\
\hline 1981 & 02 & 13 & 14 & 29 & 20 & 49 \\
1991 & 02 & 20 & 07 & 29 & 38 & 67 \\
2001 & 07 & 21 & 07 & 35 & 88 & 123 \\
2011 & 04 & 12 & 04 & 21 & 164 & 185 \\
\hline
\end{tabular}

Fonte: Instituto Paranaense de Desenvolvimento Econômico e Social (2013).

É possível perceber o grande salto da iniciativa privada a partir da década de 1990, momento em que o país viveu intensamente a política neoliberal, conforme explica Ristoff e Giolo (2006, p. 20):

[...] era o que faltava para que a iniciativa privada vislumbrasse, na educação, uma excelente oportunidade de negócio. Instituições com fins lucrativos, ágeis e competitivas, disseminaram-se pelos quadrantes do Brasil, obrigando toda a rede privada a se mobilizar na mesma direção. O resultado disso foi, como se viu, um fenômeno que pode ser resumido no trinômio: expansãodiversificação-privatização.

Gatti e Barreto (2009) trazem uma análise referente a esse aspecto. As autoras relatam que com o aumento contundente da necessidade de oferta de cursos de nível superior no país, a iniciativa privada foi o setor que absorveu a demanda. Trazem ainda a análise do contexto brasileiro no que tange à oferta de cursos de licenciatura voltados à formação de professores de anos iniciais. Os dados são apresentados na Tabela 2. 
Costa, J. M.; Pinheiro, N. A. M.; Costa, E.

Tabela 2. Evolução da oferta de cursos de Licenciatura aplicados à formação do professor de anos iniciais no contexto brasileiro

\begin{tabular}{|c|c|c|c|c|c|c|c|c|}
\hline \multirow{3}{*}{ Ano } & \multicolumn{4}{|c|}{ Instituições públicas } & \multicolumn{3}{|c|}{ Instituições privadas } & \multirow{3}{*}{ Total } \\
\hline & Federal & Estadual & Municipal & Subtotal & Particulares & Comum./ & Subtotal & \\
\hline & & & & & \multicolumn{3}{|c|}{ Confes./ Filantr. } & \\
\hline 2001 & 204 & 349 & 27 & 580 & 323 & 321 & 544 & 1.224 \\
\hline 2006 & 04 & 12 & 04 & 21 & 768 & 738 & 1.506 & 2.415 \\
\hline
\end{tabular}

Fonte: Gatti e Barreto (2009).

Na análise de Gatti e Barreto (2009), quando se fala em licenciatura, apesar da iniciativa privada apresentar a maioria das ofertas, uma diferença muito discreta é observada. As autoras concluem que nesta área, diferentemente das demais, o poder público ainda se responsabiliza pela formação dos professores.

Porém, no Estado do Paraná, encontrou-se um contexto diferente. Em uma consulta realizada no sistema e-mec (2014), foram apontados 38 cursos de Pedagogia presenciais ofertados pelo sistema público, enquanto a iniciativa privada oferta 96 cursos. Um dos pontos possíveis de análise é o tempo de distância entre os dados apresentados por Gatti e Barreto (2009), que analisa o percurso de 2001-2006, e os dados consultados em 2014, junto ao sistema e-mec.

Entre os fatores que influenciam as IES privadas a buscar cursos de Pedagogia, é possível considerar o baixo investimento, pois não exigem muitos laboratórios - como em outros das áreas de ciências humanas e sociais -, além da grande demanda por profissionais na área da educação.

\section{Carga horária total referente a estudos em matemática}

Foram analisadas as matrizes curriculares, destacando as disciplinas cujo objeto de estudo se configurava em educação matemática. Em seguida, foram somadas as horas de estudo, organizadas no Quadro 2.

Para fins de análise, primeiramente foi realizada uma verificação da carga horária total em cada um dos cursos analisados e calculada a média, conforme a seguinte fórmula:

Carga Horária CP1 + Carga Horária CP2 $+\ldots+$ Carga Horária CP $n=$ Média de horas $/$ aula TOTAL DE CP

Aplicando-se a média aritmética simples, verificou-se que os cursos apresentam a média entre 91 e 126 horas de aula em disciplinas de formação em matemática. Com base nessa informação, foi estabelecida a categoria denominada nivel, a qual foi distribuída entre 1 e 5 .

A carga horária atribuída a cada nível teve como fator de influência o número de horas/ aula que possibilitassem a distribuição em horas/semanais. Atribuiu-se ao nivel 1 a carga horária de 54 horas considerando as menores cargas horárias encontradas. Em seguida, para cada nível, foram incluídas 36 horas/aula, cuja organização está indicada no Quadro 3. 
Quadro 2. Carga horária de estudos em matemática

\begin{tabular}{|c|c|c|}
\hline Nível & Cursos & Carga Horária \\
\hline 1 & СР12; СР27 & Até 54 horas \\
\hline 2 & 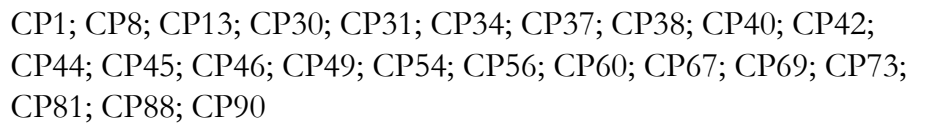 & Entre 54 e 90 horas \\
\hline 3 & $\begin{array}{l}\text { CР5; CР7; СР10; СР15; СР17; СР20; СР23; СР25; СР35; СР39; } \\
\text { CP51; СР53; СР57; СР74; СР80 }\end{array}$ & Entre 91 e 126 horas \\
\hline 4 & $\begin{array}{l}\text { СР4; СР6; СР14; СР22; СР33; СР48; СР52; СР61; СР62; СР63; } \\
\text { СР65; СР77; СР78; СР83; СР91 }\end{array}$ & Entre 127 e 162 horas \\
\hline 5 & СР11; СР19; СР47; СР55 & Mais que 162 horas \\
\hline
\end{tabular}

Fonte: Elaborado pelos autores.

Quadro 3. Distribuição dos níveis considerando a carga horária de formação

\begin{tabular}{|c|c|c|}
\hline Número de horas/aula & Número de aulas/semanais $^{4}$ & Nível \\
\hline 54 & 3 & 1 \\
\hline 90 & 5 & 2 \\
\hline 126 & 7 & 3 \\
\hline 162 & 9 & 4 \\
\hline Acima de 162 & Acima de 9 & 5 \\
\hline
\end{tabular}

Fonte: Elaborado pelos autores.

O parâmetro empregado para análise do nível foi baseado no sistema adotado pelo Ministério da Educação (MEC) na avaliação dos cursos (CPC: Conceito Preliminar de Curso). Para o presente estudo, serão considerados: nivel 1 - carga horária bastante baixa; nível 2 - carga horária baixa; nivel 3 - carga horária média; nivel 4 - carga horária alta; nivel 5 - carga horária bastante alta.

\footnotetext{
${ }^{4}$ Considerando uma distribuição em calendário letivo de 18 semanas, conforme praticado na maioria das instituições onde os cursos são ofertados.
} 
Dessa forma, a distribuição do Quadro 4 partiu da referência encontrada para o nível 3, considerado como carga horária média. A partir desta informação, foram distribuídos os niveis 1 e 2 e os 4 e 5 .

Em porcentagem, a distribuição das cargas horárias em relação aos níveis, os cursos de Pedagogia analisados podem ser assim representados.

Quadro 4. Apresentação da carga horária em níveis

\begin{tabular}{|l|c|}
\hline \multicolumn{1}{|c|}{ Nível } & Porcentagem \\
\hline 1 - bastante baixa & $3,4 \%$ \\
\hline 2 - baixa & $39 \%$ \\
\hline 3 - média & $25,4 \%$ \\
\hline $4-$ alta & $25,4 \%$ \\
\hline $5-$ bastante alta & $6,8 \%$ \\
\hline
\end{tabular}

Fonte: Elaborado pelos autores.

Com base nos estudos de Cunha (2010), Gualberto e Almeida (2009), que analisaram a porcentagem de formação que é destinada à formação em matemática do pedagogo, realizou-se uma análise do percentual da carga horária destinada à formação em matemática. Como base para o cálculo, foi considerado o que preconizam as Diretrizes Curriculares Nacionais (DCN) de Pedagogia (BRASIL, 2006):

Art. $7^{\circ} \mathrm{O}$ curso de Licenciatura em Pedagogia terá a carga horária mínima de 3.200 horas de efetivo trabalho acadêmico, assim distribuídas:

I - 2.800 horas dedicadas às atividades formativas como assistência a aulas, realização de seminários, participação na realização de pesquisas, consultas a bibliotecas e centros de documentação, visitas a instituições educacionais e culturais, atividades práticas de diferente natureza, participação em grupos cooperativos de estudos; [...].

Considerando como base de cálculo a carga horária mínima de 2.800 horas de formação, a Tabela 3 mostra a relação em porcentagem entre a carga horária geral e a dedicada à formação em matemática. 
Tabela 3. Porcentagem da carga horária total disponibilizada para formação em matemática

\begin{tabular}{cccccc}
\hline $\begin{array}{c}\text { Carga } \\
\text { horária total }\end{array}$ & $\begin{array}{c}\text { Número } \\
\text { de horas/ } \\
\text { aula }\end{array}$ & $\begin{array}{c}\text { Porcentagem } \\
\text { de formação } \\
\text { em matemática }\end{array}$ & $\begin{array}{c}\text { Total de } \\
\text { cursos }\end{array}$ & $\begin{array}{c}\text { Número } \\
\text { de cursos }\end{array}$ & $\begin{array}{c}\text { Número de } \\
\text { cursos em } \\
\text { porcentagem }\end{array}$ \\
\hline \multirow{2}{*}{$\mathbf{8 0 0} \mathbf{h}$} & 54 & $1,9 \%$ & & 02 & $3,4 \%$ \\
& 90 & $3,2 \%$ & 59 & 23 & $39 \%$ \\
& 126 & $4,5 \%$ & & 15 & $25,4 \%$ \\
& 162 & $5,8 \%$ & 04 & $6,4 \%$ \\
\hline
\end{tabular}

Fonte: Elaborado pelos autores.

Conforme verificado na Tabela 3, a média de horas destinadas para formação em matemática do professor de anos iniciais, na maioria das instituições, está em torno de 3,2\%. Nesse parâmetro, está próximo dos valores encontrados por Cunha (2010), que analisou cursos brasileiros, e Gualberto e Almeida (2012), que focaram suas análises no Estado de São Paulo. Desta forma, é possível perceber que a maioria dos cursos de Pedagogia possui uma carga horária baixa destinada a estudos em matemática, representando 39\% dos cursos analisados.

Isso poderá confirmar o alerta de Pavanello (2004) com relação à dificuldade dos professores em desenvolver os conteúdos de matemática na formação dos anos iniciais do Ensino Fundamental, pois se considerar os níveis 1 e 2 somados, conclui-se que 42,4\% possuem formação para a educação matemática inferior a noventa horas. Diante da complexidade desta área de estudo, cabe uma reflexão acerca da melhor preparação do futuro docente para o trabalho com matemática.

\section{Disciplinas que compõem a formação em matemática}

Um terceiro ponto de análise feito no estudo das matrizes curriculares foi o quadro de disciplinas que propiciam a formação em matemática do pedagogo no Estado do Paraná. Primeiramente, foram elencadas todas as disciplinas que remetem a essa área de formação. Por meio dessa descrição, foi possível categorizá-las em: (1) Matemática básica; (2) Estatística; (3) Metodologia para o ensino de matemática; (4) Metodologia para o ensino de matemática e ciências; (5) Construção do pensamento matemático; (6) Educação financeira.

As disciplinas foram distribuídas nas categorias elencadas, sendo sua disposição apresentada no Quadro 5.

Analisando o Quadro 6, destaca-se a presença de disciplinas de matemática básica, considerando-se a importância do estudo das bases dos conteúdos de matemática, precedente às metodologias, para a formação do pedagogo. Os três cursos em que se encontrou essa abordagem pertencem à iniciativa privada, o que caberia, em outro momento, uma análise sobre por que apenas as instituições privadas mostraram essa preocupação. 
Costa, J. M.; Pinheiro, N. A. M.; Costa, E.

Quadro 5. Disciplinas voltadas ao estudo da matemática

\begin{tabular}{|c|c|c|}
\hline Curso & Descrição da categoria & Categoria \\
\hline CP35; CР61; СР65 & Prevê o estudo de conceitos da matemática. & $\begin{array}{l}\text { 1. Matemática } \\
\text { Básica }\end{array}$ \\
\hline $\begin{array}{l}\text { СР11; СР14; СР39; СР45; СР47; } \\
\text { СР51; СР52; СР53; СР61; СР65; } \\
\text { СР77; СР78; СР91 }\end{array}$ & $\begin{array}{l}\text { Estudo de estatística, geralmente com foco na } \\
\text { estatística escolar. }\end{array}$ & 2. Estatística \\
\hline 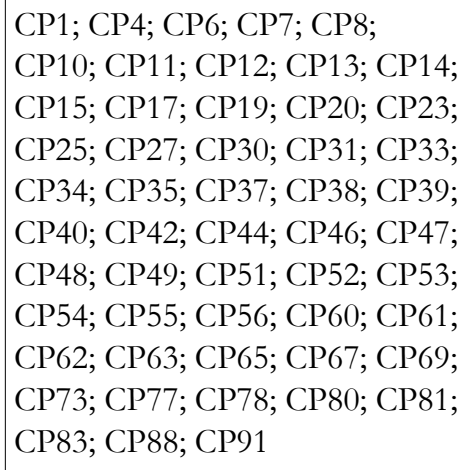 & $\begin{array}{l}\text { Estuda fundamentos teóricos e metodológicos } \\
\text { para o ensino de matemática, voltados à } \\
\text { Educação Infantil e ao Ensino Fundamental. }\end{array}$ & $\begin{array}{l}\text { 3. Metodologia } \\
\text { para ensino da } \\
\text { Matemática }\end{array}$ \\
\hline СР5; СР22; СР57; СР74; СР90 & $\begin{array}{l}\text { Estuda fundamentos teóricos e metodológicos } \\
\text { para o ensino de matemática e das ciências } \\
\text { voltados à Educação Infantil e ao Ensino } \\
\text { Fundamental. Apenas parte da carga horária é } \\
\text { destinada para a formação em matemática. }\end{array}$ & $\begin{array}{l}\text { 4. Metodologia } \\
\text { para ensino da } \\
\text { Matemática e } \\
\text { Ciências }\end{array}$ \\
\hline CP80 & Não foi possível localizar ementa. & $\begin{array}{l}\text { 5. Construção } \\
\text { do Pensamento } \\
\text { Matemático }\end{array}$ \\
\hline CP83 & Formação para finanças. & $\begin{array}{l}\text { 6. Educação } \\
\text { Financeira }\end{array}$ \\
\hline
\end{tabular}

Fonte: Elaborado pelos autores.

Gomes (2006) faz um levantamento acerca dos estudos realizados sobre a formação em matemática de professores para Educação Básica, e entre as perspectivas de análise, foram identificadas dificuldades em relação às noções acerca do conhecimento científico na área das ciências entre os alunos ingressantes nos cursos de Pedagogia. Sobre esse aspecto, a autora escreve:

Por este motivo, uma alfabetização científica e mais especificamente uma alfabetização matemática torna-se imprescindível, pois pouco poderão fazer se não tiverem domínio dos conceitos matemáticos que deverão explorar 
com seus alunos e também, noções de como poderão fazer este trabalho. Além disso, é preciso que superem os obstáculos que carregam de suas experiências com a matemática, para que também possam contribuir para a superação dos obstáculos que porventura seus alunos apresentarem e, consequentemente, conceberem a matemática de uma maneira diferenciada, menos fóbica. (GOMES, 2006, p. 61)

Outro ponto verificado foi quanto à presença do estudo de estatística em $22 \%$ das matrizes curriculares analisadas. A importância de tal formação para o pedagogo já se justifica pelas próprias avaliações externas de acompanhamento das instituições, que acontecem com base em dados estatísticos. Não compreender as informações divulgadas e até mesmo como estas são coletadas e analisadas, pode levar o pedagogo a uma visão simplista do contexto educacional. A formação crítica, debatida pelos mais renomados educadores, não é baseada apenas no questionamento e argumentação da escrita ou da fala, mas inclui ainda as demais áreas do saber, entre elas a matemática.

A relevância da presença do ensino de estatística nos cursos de Pedagogia é discutida por Lopes (2008, p. 69): “Acreditamos que um dos principais impedimentos ao ensino efetivo de probabilidade e estatística na Educação Básica refira-se à formação dos professores que ensinam matemática nesses níveis de ensino: Educação Infantil, Ensino Fundamental e Ensino Médio”.

Considerando que a docência na Educação Infantil e os anos iniciais do Ensino Fundamental são áreas de trabalho de pedagogos - além do trabalho como gestor - a estatística está presente em todas as etapas da Educação Básica. Se houver fragilidade na formação desse docente, certamente a deficiência se estenderá para a formação de seus alunos. A autora ainda complementa: "A formação dos professores, atualmente, não incorpora um trabalho sistemático sobre estocástica, dificultando a possibilidade desses profissionais de desenvolverem um trabalho significativo com essa temática nas salas de aula da Educação Básica.” (LOPES, 2008, p. 70).

Portanto, a estatística não pode ser uma disciplina alheia à realidade, pois seu objetivo principal é contribuir para a formação intelectual do acadêmico, de maneira autônoma, fazendo com que o conhecimento aprendido possa lhe proporcionar condições para compreensão e participação das discussões em torno da educação.

Sem dúvida, o processo educacional é inerentemente político e nós, professores, constantemente tomamos decisões e assumimos ações que expressam o quanto não somos politicamente neutros. Assim, um primeiro desafio referese a nossa opção em incluir ou excluir alguns assuntos do currículo de nossa disciplina. Nessa ação estamos efetivando nossa posição política, quando legitimamos certas crenças e deslegitimamos outras (LOPES, 2008, p. 64)

Por fim, foi analisada, nas matrizes curriculares, a presença de disciplinas que tratam sobre fundamentos e metodologias para o ensino de matemática. Com exceção de CP45, todas as demais matrizes apresentam claramente disciplinas voltadas ao estudo de metodologias aplicadas à educação matemática. Cabe ressaltar que, como não foi possível o acesso ao ementário do curso da referida instituição (CP45), não se pode definir ao certo se há mesmo a ausência de tal enfoque na formação do pedagogo. Esse dado reforça a afirmação de Curi (2004) sobre 
a ênfase nas metodologias de como ensinar, que apesar de marcar a formação dos professores nas décadas de 1970 a 1980, ainda apresenta-se forte nos currículos atuais.

Curi (2004), ao pesquisar as matrizes curriculares de cursos de Pedagogia, verifica que as ementas possuem enfoques muito diferenciados. De forma geral, tratam sobre procedimentos didáticos dos conteúdos de matemática, sendo que algumas mostram uma tentativa de resgate do trabalho com o conteúdo.

Cabe ressaltar que foi ainda verificado que $8,5 \%$ dos cursos organizam os estudos de metodologia da matemática em conjunto com a formação para as ciências. Diante desta informação, entende-se que seria conveniente realizar uma nova distribuição na carga horária de formação para a matemática, considerando as horas dessas disciplinas de forma parcial.

Quadro 6. Revisão da carga horária para formação em matemática

\begin{tabular}{|c|c|c|}
\hline Curso & Carga Horária Geral/Nível & Carga Horária Revisada/Nível \\
\hline CP5 & $102 \mathrm{~h} /$ nível 3 & $51 \mathrm{~h} /$ nível 1 \\
\hline $\mathrm{CP} 22$ & $136 \mathrm{~h} /$ nível 4 & $68 \mathrm{~h} /$ nível 2 \\
\hline $\mathrm{CP} 57$ & $120 \mathrm{~h} /$ nível 3 & $60 \mathrm{~h} /$ nível 2 \\
\hline CP74 & $120 \mathrm{~h} /$ nível 3 & $60 \mathrm{~h} /$ nível 2 \\
\hline CP90 & $72 \mathrm{~h} /$ nível 2 & $36 \mathrm{~h} /$ nível 1 \\
\hline
\end{tabular}

Fonte: Elaborado pelos autores.

Com essa nova revisão, a Tabela 1 foi reelaborada, sendo seu resultado apresentado no Quadro 7.

Quadro 7. Apresentação da carga horária em níveis

\begin{tabular}{|l|c|}
\hline \multicolumn{1}{|c|}{ Nível } & Porcentagem \\
\hline 1 - bastante baixa & $6,8 \%$ \\
\hline 2 - baixa & $42,4 \%$ \\
\hline 3 - média & $20,3 \%$ \\
\hline $4-$ alta & $23,7 \%$ \\
\hline $5-$ bastante alta & $6,8 \%$ \\
\hline
\end{tabular}

Fonte: Elaborado pelos autores. 
Percebe-se, pelos detalhes presentes na matriz curricular, que houve aumento dos cursos que possuem carga horária bastante baixa e carga horária baixa para formação em matemática. Consequentemente, diminuíram os cursos que possuem carga horária média e alta de disciplinas com enfoque em matemática.

Fiorentini (2008) alerta para essa situação ao colocar como "problema crônico" o fato dos cursos de Pedagogia possuírem uma carga horária muito reduzida para a formação didático-pedagógica em matemática. Esse cenário se torna ainda mais agravado, segundo o autor, pela superficialidade nos conhecimentos conceituais de matemática:

Além da falta de um domínio conceitual da matemática, os alunos-docentes que ingressam nesses cursos de formação docente trazem crenças e atitudes geralmente negativas e pré-conceituosas em relação à matemática e seu ensino. Relação essa decorrente de uma história de fracasso escolar e da construção de uma imagem de que a matemática é difícil e que nem todos são capazes de aprendê-la. O não enfrentamento ou tratamento desse problema, durante a formação inicial, tem sérias implicações na prática docente desses alunos e alunas (FIORENTINI, 2008, p. 57).

Contudo, na presente pesquisa, também foram encontrados diferenciais na formação do pedagogo. O curso CP80 proporciona um enfoque na construção do pensamento matemático, contudo, como não foi possível acessar a ementa dessa disciplina, têm-se apenas as hipóteses que seu objetivo pode ser: o raciocínio lógico-matemático apoiado nas teorias da psicologia ou o pensamento matemático com enfoque antropológico e/ou sociológico.

Outro curso que se destaca pela oferta de diferencial foi o CP83, o qual aborda estudos sobre finanças. Esta é uma área muito interessante, por um lado para o pedagogo gestor, o qual trabalhará com esse conteúdo no dia a dia da administração escolar. Além disso, na atuação como docente, poderá proporcionar aos seus alunos a formação para esta área, que pode ser de grande relevância para o cotidiano do educando.

\section{Considerações}

A presente pesquisa não buscou apontar ou classificar os cursos de Pedagogia. Sua preocupação central foi a formação do pedagogo, o qual é habilitado para a docência da Educação Infantil e Anos Iniciais do Ensino Fundamental, e sua preparação para o trabalho com o ensino de matemática.

Foi possível perceber a riqueza dos currículos com a inclusão de estudos bastante pertinentes para a formação geral do futuro educador, que abrem espaço para verificações mais profundas de suas abordagens.

Pela análise realizada, verificou-se um número expressivo de cursos que contemplam uma carga horária reduzida para a formação em matemática se comparado à média praticada, que foi de 110 horas/aula, levando em conta as disciplinas de metodologia de matemática e ciências em sua carga horária integral, e 107 horas/aula, se consideradas estas mesmas disciplinas com carga horária parcial. 
Conforme apresentado nos estudos teóricos pelos diferentes autores consultados, se o professor sentir dificuldade com os conceitos de matemática, essa dificuldade certamente será repassada a seus alunos. É importante que se considere que a frágil formação em matemática interfere diretamente nas relações do estudante com o meio, nas situações cotidianas, bem como para prosseguimento dos estudos.

Apesar de pouco praticada, analisando-se as ementas, destaca-se neste estudo a importância: (i) da disciplina de estatística, por contribuir tanto para a atuação docente, quanto para a gestão escolar; (ii) da formação em finanças, pois ela, além de estar diretamente relacionada à vida cotidiana de todos os cidadãos, torna-se uma ferramenta importante na gestão escolar; (iii) de matemática básica, por ser considerada uma importante base de formação do professor (pois não se pode ensinar o que não se conhece), para conhecimento dos conceitos de matemática, propiciando posterior compreensão dos métodos e fundamentos necessários ao exercício da docência.

Por fim, conclui-se que, de forma geral, as matrizes curriculares para a formação do pedagogo, no Estado do Paraná, têm mostrado uma abordagem tímida para a formação em matemática do futuro docente. A consequência disso pode levar à precariedade da formação básica dos alunos, pela falta de preparo do professor, o que acarretará uma fragilidade ainda maior futuramente, pois os alunos que hoje estão sendo formados serão os futuros docentes.

\section{Referências}

BRASIL.Conselho Nacional de Educação. Resolução CNE/CP no 1 de 15 de maio de 2006: institui as diretrizes curriculares nacionais para o curso de graduação em Pedagogia, licenciatura. Diário Oficial da União, Brasília, 16 maio 2006. Seção 1, p. 11.

BRASIL. Ministério da Educação. Parâmetros curriculares nacionais: ensino fundamental - introdução. Rio de Janeiro: DP\&A, 1997.

Referencial curricular nacional para a educação infantil. Brasília: SEF, 1998.

CARZOLA, I. M.; SANTANA, E. R. S. Concepções, atitudes e crenças em relação à matemática na formação do professor da educação básica. In: REUNIÃO ANUAL DA ANPEd, 28., 2005, Caxambú. Anais eletônicos... Caxambú: ANPEd, 2005. Disponível em: <http://www.ufrrj.br/emanped/paginas/conteudo_producoes/docs_28/concepcoes.pdf > . Acesso em: 19 jun. 2014.

CUNHA, D. R. A matemática na formação de professores dos anos iniciais do ensino fundamental: relações entre a formação inicial e a prática pedagógica. 2010. 107 f. Dissertação (Mestrado em Educação em Ciências e Matemática) - Faculdade de Física, Pontifícia Universidade Católica do Rio Grande do Sul, Porto Alegre, 2010.

CURI, E. Formação de professores polivalentes: uma análise de conhecimento para ensinar matemática e de crenças e atitudes que interferem na constituição desses conhecimentos. 2004. 278 f. Tese (Doutorado em Educação Matemática) - Pontifícia Universidade Católica de São Paulo, São Paulo, 2004. 
CURI, E. A formação matemática de professores dos anos iniciais do ensino fundamental face às novas demandas brasileiras. Revista Iberoamerica de Educación, Madrid, n. 37/5, p. 1-9, 2005. Disponível em: <http://www.rieoei.org/deloslectores/1117Curi.pdf > . Acesso em: 19 jun. 2014.

e-MEC. Disponível em: <http://emec.mec.gov.br/>. Acesso em: 5 ago. 2014.

FIORENTINI, D. A pesquisa e as práticas de formação de professores de matemática em face das políticas públicas no Brasil. Bolema, Rio Claro, v. 21, n. 29, p. 43-70, 2008.

GAIO, A.; DUARTE, T. O. O conhecimento matemático do professor de $1^{\circ}$ ciclo. In: ENCONTRO DE INVESTIGAÇÃO EM EDUCAÇÃO MATEMÁTICA, 12., 2003, Évora. Atas... Lisboa: Sociedade Portuguesa de Investigação em Educação Matemática, 2003. Disponível em: <http://spiem.pt/DOCS/ATAS_ENCONTROS/2003/2003_05_ AGaio.pdf>. Acesso em: 19 jun. 2014.

GATTI, B. A. Educação, escola e formação de professores: políticas e impasses. Educar em Revista, Curitiba, n. 50, p. 51-67, out/dez. 2013. Disponível em: <http://www.scielo.br/ pdf/er/n50/n50a05.pdf>. Acesso em: 12 fev. 2016.

GATTI, B.; BARRETO, E. S. S. (Coord.). Professores do Brasil: impasses e desafios. Brasília: UNESCO, 2009.

GOMES, M. G. Obstáculos na aprendizagem matemática: identificação e busca de superação nos cursos de formação de professores das séries iniciais. 2006. 161 f. Tese (Doutorado em Educação Científica e Tecnológica) - Universidade Federal de Santa Catarina, Florianópolis, 2006.

GUALBERTO, P. M. A.; ALMEIDA, R. Formação de professores das séries iniciais, algumas considerações sobre a formação matemática e a formação dos professores das licenciaturas em pedagogia. Olhar de Professor, Ponta Grossa, v. 12, n. 2, p. 287-308, 2009.

INEP. IDEB: resultados e metas. Disponível em: < http://ideb.inep.gov.br/resultado/ resultado/resultadoBrasil.seam?cid=375920> . Acesso em: 26 dez. 2015.

INSTITUTO PARANAENSE DE DESENVOLVIMENTO ECONÔMICO E SOCIAL. Base de dados do Estado- BDEweb. Disponível em: < http://www.ipardes.pr.gov.br/imp/ index.php>. Acesso em: 22 dez. 2013.

LOPES, C. E. O ensino da estatística e da probabilidade na educação básica e a formação dos professores. Caderno CEDES, Campinas, v. 28, n. 74, p. 57-73, jan./abr. 2008.

MARCONI, M. A.; LAKATOS, E. M. Fundamentos de metodologia científica. 5. ed. São Paulo: Atlas, 2003.

MICHELOTTO, M. R. Políticas de formação dos professores das séries iniciais da escola, no Brasil. In: LA UNIVERSIDAD COMO OBJETO DE INVESTIGACION, 3., 2009, Cordoba. Anais... Cordoba: Universidad Nacional de Cordoba, 2009. 1 CD-ROM.

MOREIRA, H.; CALEFFE, L. G. Metodologia da pesquisa para o professor pesquisador. 2. ed. Rio de Janeiro: Lamparina, 2008. 
Costa, J. M.; Pinheiro, N. A. M.; Costa, E.

PAVANELLO, R. M. (Org.). Matemática nas séries iniciais do ensino fundamental: a pesquisa em sala de aula. São Paulo: Biblioteca do Educador Matemático, 2004.

RISTOFF, D.; GIOLO, J. (Org.). Educação superior brasileira 1991-2004. Brasília: INEP, 2006.

Artigo recebido em 14/09/2014. Aceito em 21/12/2015.

Endereço para contato: Avenida Monteiro Lobato, s/n, Km 04, CEP: 84016-210, Ponta Grossa, PR, Brasil. 